\title{
Correction to: Diagnostic performance of an unenhanced MRI exam for tumor follow-up of the optic pathway gliomas in children
}

\author{
Pierre Marsault ${ }^{1} \cdot$ Stéphane Ducassou ${ }^{2} \cdot$ Fanny Menut $^{1} \cdot$ Pierre Bessou $^{1} \cdot$ Marion Havez-Enjolras $^{1}$. \\ Jean-François Chateil ${ }^{1,3}$
}

Published online: 22 April 2019

(C) Springer-Verlag GmbH Germany, part of Springer Nature 2019

\section{Correction to: Neuroradiology 2019 \\ https://doi.org/10.1007/s00234-019-02198-w}

In the article "Diagnostic performance of an unenhanced MRI exam for tumor follow-up of the optic pathway gliomas in children", Table 2 data were not presented correctly, with results placed beneath an incorrect heading. Confidence intervals have been added. The original article has been corrected. The corrected table is:

Table 2 Diagnostic performance of an unenhanced MRI in the follow-up of optical pathway gliomas in children

\begin{tabular}{lllllllll}
\hline Variable & TP Findings & TN Findings & FP Findings & FN Findings & Sensitivity $(\%)^{\mathrm{a}}$ & Specificity $(\%)^{\mathrm{a}}$ & PPV $(\%)^{\mathrm{a}}$ & NVP(\%) \\
\hline Reader 1 & 22 & 21 & 2 & 3 & $88.0(68.8-97.5)$ & $91.3(72.0-99.0)$ & $91.7(74.0-97.7)$ & $87.5(70.6-95.3)$ \\
Reader 2 & 21 & 23 & 0 & 4 & $84.0(63.9-95.5)$ & $100(85.7-100)$ & $100(84.5-100)$ & $85.2(70-93.4)$ \\
\hline
\end{tabular}

$T P$ true-positive, $T N$ true-negative, $F P$ false positive, $F N$ false-negative, $P P V$ positive predictive value, $N V P$ negative predictive value

${ }^{a}$ Data in parentheses are $95 \%$ confidence interval

Publisher's note Springer Nature remains neutral with regard to jurisdictional claims in published maps and institutional affiliations.

The online version of the original article can be found at https://doi.org/ 10.1007/s00234-019-02198-w

Pierre Marsault

pierremarsault974@gmail.com

1 Department of Pediatric Radiology, Pellegrin Children's Hospital, Place Amelie Raba-Leon, 33076 Bordeaux, France

2 Department of Pediatric Hematology and Oncology, Pellegrin Children's Hospital, Place Amelie Raba-Leon, 33076 Bordeaux, France

3 CRMSB, UMR 5536, CNRS/University of Bordeaux, 146 rue Leo, Saignat, 33076 Bordeaux Cedex, France 